\title{
Ultrastructural studies on the neurosecretory cells in the pars intercerebralis of larvae of tasar silkworm, Antheraea mylitta (D) eco-race Bhandara (Lepidoptera: Saturniidae)
}

Deepak Dewaji Barsagade and Shruti Arvind Gharade*

Department of Zoology, RTM Nagpur University, Nagpur 440033, India

\section{Abstract}

The cerebral neurosecretory cells (NSC) constitute four paired groups, medial (MNC), lateral (LNC-I, LNC-II) and posterior (PNC) in the brain of larvae of tasar silkworm Antheraea mylitta (D) Eco-race Bhandara. The MNC is the largest groups of peptidergic neurosecretory cells and are located in the pars intercerebralis region. The transmission electron microscopic (TEM), ultrastructure of the NSC confirmed the presence of mitochondria, endoplasmic reticulum, Golgi bodies, lysosomes and neurosecretory granules. The median neurosecretory cells shows secretory activity and release of secretory products, the neurosecretory granules (NSG) in the axons of NSC as well as the blood sinus.

Received : 18 Apr 2014

Accepted : 22 Sep 2014

Keywords:

Antheraea mylitta, Neurosecretory cells, (C) 2014 The Korean Society of Sericultural Sciences Int. J. Indust. Entomol. 29(1), 120-127 (2014) ultrastructure, neurosecretory granules

\section{Introduction}

In tasar silkworm A. mylitta larva, the neurosecretory cells in the brain are found in four groups viz., MNC, LNC-I, LNCII and PNC. The MNC are situated in the pars intercerebralis of protocerebrum.

The neurosecretory cells consist of nucleus at the center and various cell organelles in the perikarya. The cell organelles include ribosomes, Golgi complexes and endoplasmic reticulum. All organelles are involved in the synthesis of neurosecretory material (NSM) in the form of granules (Nishiitsutsuji-uwo, 1960).

The ultrastructure of intracellular organization and subcellular mechanism associated with the synthesis and release of NSM by the MNC in the brain was studied earlier in some Lepidoptera
(Ichikawa and Nishiitsutsuji-uwo, 1959, 1960; Ichikawa and Takahashi, 1959; Nishiitsutsuji-uwo, 1960). There is however, no information on the ultrastructure of MNC in tasar silkworms.

The present study was therefore, undertaken to study the ultrastructure of the MNC, secretion of neurosecretory granules (NSG) and release of NSM in the pars intercerebralis of brain in tasar silkworm A. mylitta (D) eco-race Bhandara.

\section{Material Methods}

Tasar silkworm, Antheraea mylitta (D) eco-race Bhandara is the principle nonmulberry silk producing insect and is cultivated in the tropical forest of India including the region of Bhandara, Chandrapur and Gadchiroli District of Vidarbha

\section{${ }^{*}$ Corresponding author.}

Shruti Arvind Gharade

Department of Zoology, RTM Nagpur University, Nagpur 440033, India.

Tel: Mob.-09371164767

E-mail: shruti.gharade@gmail.com 
in the Maharashtra state, India. The non-dipausing cocoons of Antheraea mylitta (D) eco-race Bhandara were brought from the forest of Gadchiroli to the laboratory and rearing was carried out at the insectaries of the Department of Zoology, RTM Nagpur University, Nagpur, India. For transmission electron microscopic studies, the brain of the first to fifth instar larvae of A. mylitta were dissected gently and fixed in $2.5 \%$ glutaraldehyde and $2 \%$ paraformaldehyde in $0.1 \mathrm{M}$ sodium phosphate buffer $(\mathrm{pH} 7.3$ ) for 12 hours at $4^{\circ} \mathrm{C}$. After washed in buffer, the samples were post fixed in $1 \%$ osmium tetraoxide $\left(\mathrm{OsO}_{4}\right)$ for 1 hour at $4^{\circ} \mathrm{C}$. The samples were dehydrated in an ascending grade of acetone, infiltrated and embedded in araldite CY 212 (TAAB, UK). Thick Sections $(1 \mu \mathrm{m})$ were cut with an ultramicrotome, mounted on to glass slides, stained with aqueous toluidine blue and observed under a light microscope for gross observation of the area and quality of the tissue fixation. For electron microscope examination, thin sections of grey-silver colour interference (70$80 \mathrm{~nm}$ ) were cut and mounted onto 300 mesh- copper grids. Sections were stained with alcoholic uranyl acetate and alkaline lead citrate, washed gently with distilled water and observed under a Morgagni 268D transmission electron microscope (Fei Company, The Netherlands) at an operating voltage $80 \mathrm{kV}$. Images were digitally acquired by using a CCD camera (Mega view III, Fei Company) attached to the microscope at All India Institute of Medical Sciences, (AIIMS) New Delhi, India.

\section{Results}

\section{Ultrastructure of median neurosecretory cells}

The medial neurosecretory cells are spherical or oval in shape. The plasma membrane is well differentiated and some canaliculies are associated with the plasma membrane. The electron microscopic studies show the presence of nucleus at the center of the cells. Most of the region of the perikaryon is filled with concentric long granular endoplasmic reticulum (GER), mitochondria (MT), Golgi complexes (GC) in the close vicinity to NSG (Fig. 1). The mitochondria are rod shaped. The NSG are often accumulated throughout the cytoplasm and axonal endings.

\section{Nucleus (N)}

Nucleus is situated at the center of the cell, spherical or oval in

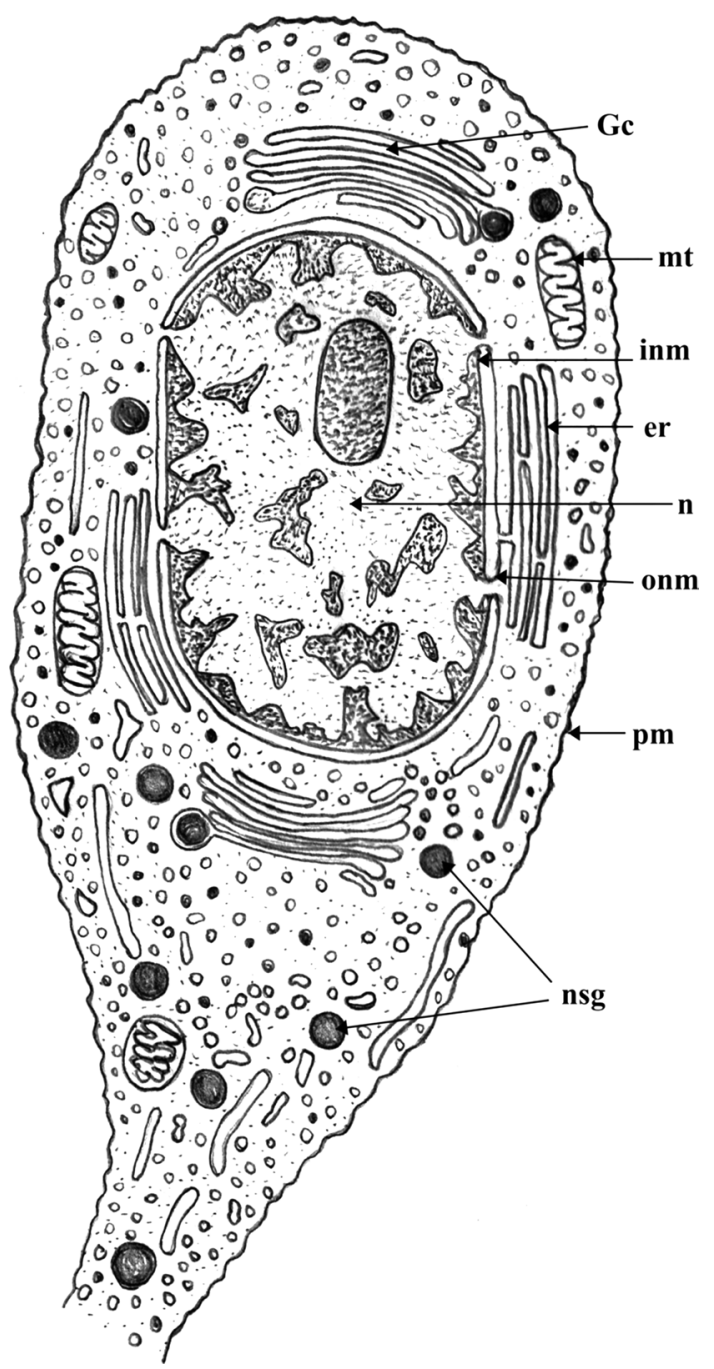

Fig. 1. Neurosecretory cell in the pars intercerebralis of $A$. mylitta showing various cell organelles. Nucleus $(\mathrm{N})$, outer nuclear membrane (ONM), inner nuclear membrane (INM), plasma membrane (PM), Golgi complex (GC), mitochondria (MT), endoplasmic reticulum (ER) and neurosecretory granules (NSG) (Diagrammatic illustration).

shape and contains dispersed chromatin material and prominent nucleoli of irregular shape. The electron micrographic study reveals the nuclear membrane (NM) consisting of two layers, the inner thick and outer thin layers. Sometimes, the outer layer is associated with the endoplasmic reticulum.

The nucleus contains many dense granules, evenly distributed or aggregated into small colloids. The nucleolus appears as a dark area with irregular shape (Fig. 1).

\section{Cytoplasmic organelles and neurosecretion}

The cytoplasm of neurosecretory cells in the pars intercerebralis 
is well equipped with the cytoplasmic is organelles viz., mitochondria, endoplasmic reticulum, Golgi complex and lysosomes. The cytoplasm also filled with electron-dense as neurosecretory granules (NSG) (Fig. 1).

\section{Mitochondria (MT)}

In the cytoplasm of MNC, numerous filamentous, rod like or sometimes beaded like mitochondria occur. They stain densely. The mitochondria are distributed at random or sometimes gather together in aggregates. Mitochondria consist of double membranes and cristae.

\section{Endoplasmic reticulum (ER)}

The endoplasmic reticulum (ER) is randomly scattered through the cytoplasm of the neurosecretory cells (Fig. 1). Most of the membranes of ER are rough-surfaced, interchanged with a few smooth-surfaced (SER) reticulae. The ribosomes were associated with the rough endoplasmic reticulum (RER).

\section{Golgi complex (GC)}

The Golgi complex is composed of stacks of smooth membrane and vesicles. The Golgi lamellae sometimes contain NSG at their terminal ends while, an electron dense material has been seen in the tubules and vesicles indicating involvement of Golgi complex in the synthesis of NSG. The NSG show gradual increase in their size after being budded off from the Golgi complex. The fully formed NSG are bounded by a membrane (Fig. 1).

\section{Neurosecretory Granules (NSG)}

The neurosecretory granules are observed in the cytoplasmic perikarya of NSC as the fine, spherical or ellipsoidal, electrondense elementary granules (EG) (Fig. 1). The granules were relatively uniform in electron density, and they measure about $500-2500 \AA$ ( $1500 \AA$ in diameter). The NSG are often observed in the axonal endings of the neurosecretory cells.

\section{Synthesis of the NSM}

The MNC show synthesis of fine, spherical or ellipsoidal, electron-dense NSG. The NSG are formed in close vicinity of the mitochondria, Golgi zone and rough endoplasmic reticulum. The NSG are frequently encountered near the Golgi zone.
The NSG are scanty and are enveloped with membranous covering. The NSG are evenly distributed in the perikarya of NSC.

Release and transport of NSM

The NSG are migrated along the axons of neurosecretory cells of the brain to the corpora cardiaca via neurosecretory pathways. The direct release of neurosecretory material appears from the perikarya of neurosecretory cells into the canaliculi, communicated to the blood sinus. The canaliculi are closely associated with the plasma membrane of NSC. The NSM is directly released from cell into the haemolymph through the process of exocytosis.

\section{Ultrastructure of MNC during larval development}

\section{Ultrastructure of NSC in I instar}

The neurosecretory cells in the first instar larva are observed in the pars intercerebralis of brain. The nuclei are situated at the center of the cell and measures about $5.5 \mu \mathrm{m}$. Nuclei are oval in shape with irregular outline, the nuclear membrane is double layered. The perikarya of NSC contain numerous mitochondria, endoplasmic reticulum and Golgi apparatus. The cell organelles are closely associated with formation of NSM in the form of NSG. The small electron dense granules are observed in the cytoplasm as well as axonal endings of the MNC. The NSG measure about 472 $\AA$ in diameter. Some canaliculi are also associated with the plasma membrane of MNC (Fig. 2-3 and Fig. 13).

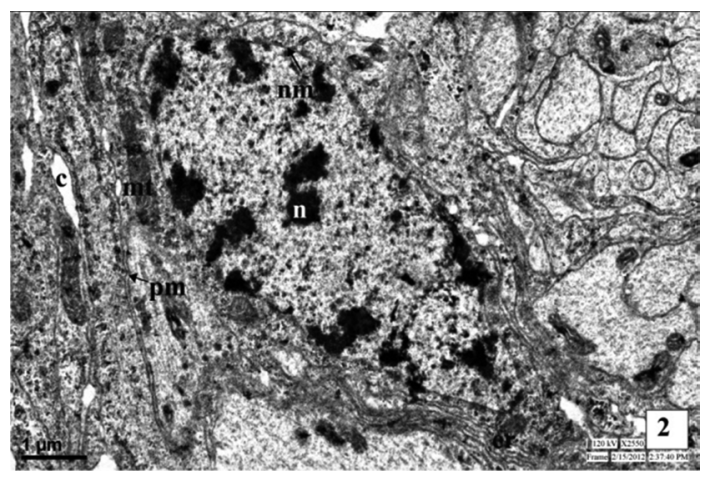

Fig. 2. Neurosecretory cell in the pars intercerebralis of first instar larva of Antheraea mylitta showing nucleus (N), nuclear membrane (NM), plasma membrane (PM), mitochondria (MT), endoplasmic reticulum (ER), canaliculi $(\mathrm{C})$. 


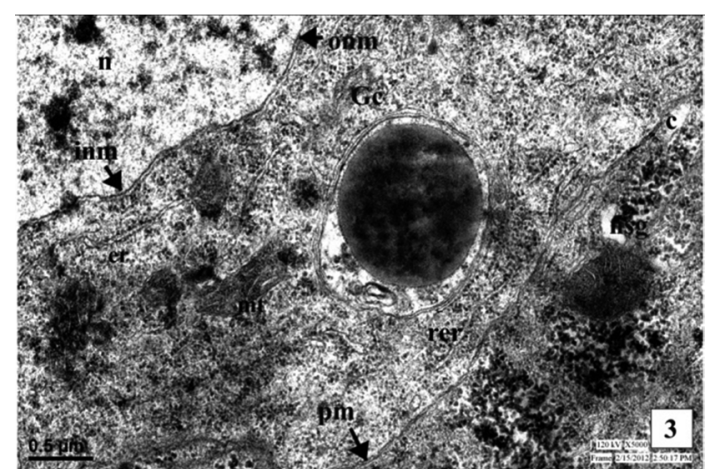

Fig. 3. Neurosecretory cell in the pars intercerebralis of first instar larva showing nucleus $(\mathrm{N})$, outer nuclear membrane (ONM), inner nuclear membrane (INM), plasma membrane (PM), endoplasmic reticulum (ER), mitochondria (MT), Golgi complex (GC), neurosecretory granules (NSG) and canaliculi (C).

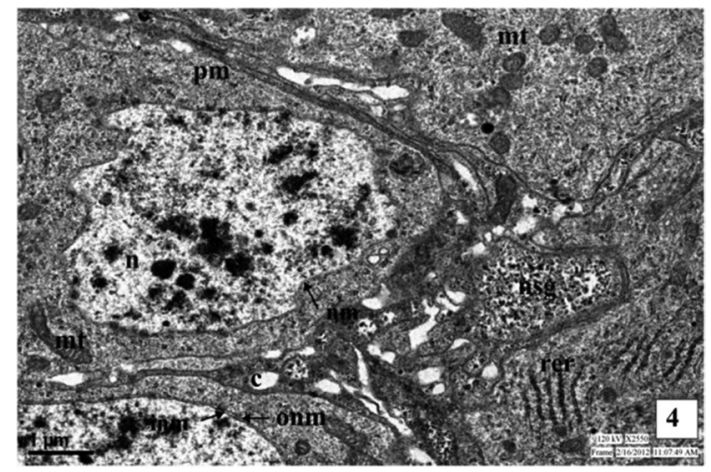

Fig. 4. Neurosecretory cell in the pars intercerebralis of second instar larva of $A$. mylitta showing nucleus $(\mathrm{N})$, nuclear membrane (NM), outer nuclear membrane (ONM), inner nuclear membrane (INM), plasma membrane (PM), rough endoplasmic reticulum (RER), mitochondria (MT), neurosecretory granules (NSG) and canaliculi (C).

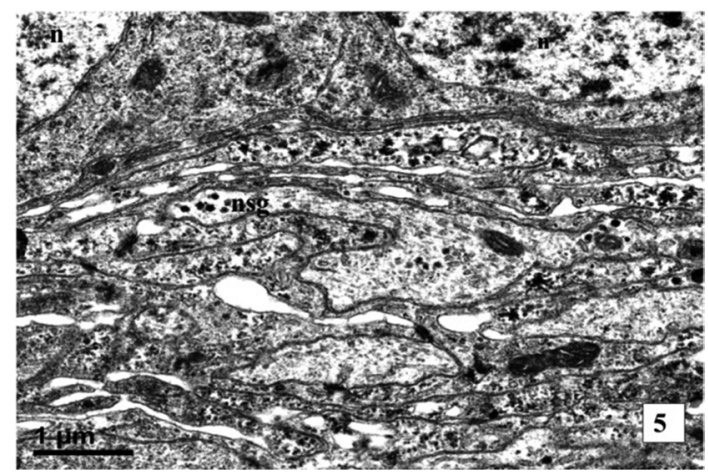

Fig. 5. Neurosecretory pathways in the pars intercerebralis of second instar larva showing the transport of neurosecretory granules (NSG).

\section{Ultrastructure of NSC of II instar}

The spherical nucleus is placed centrally, measured about

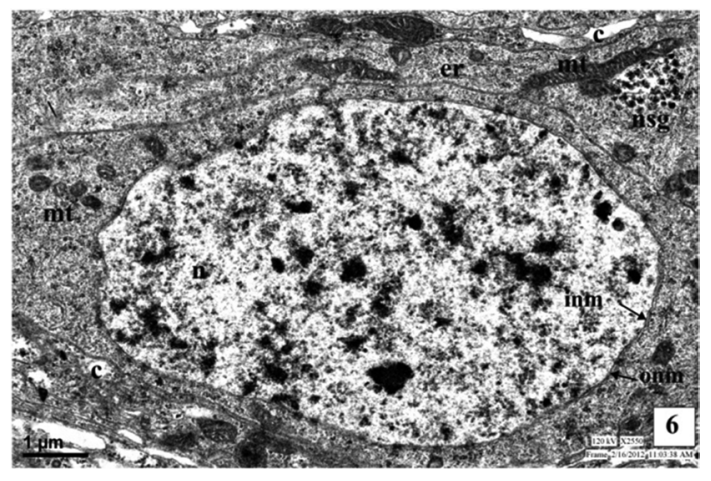

Fig. 6. Neurosecretory cell in the pars intercerebralis of third instar larva of $A$. mylitta showing nucleus ( $\mathrm{N})$, outer nuclear membrane $(\mathrm{ONM})$, inner nuclear membrane (INM), endoplasmic reticulum (ER), mitochondria (MT), neurosecretory granules (NSG) and canaliculi (C).

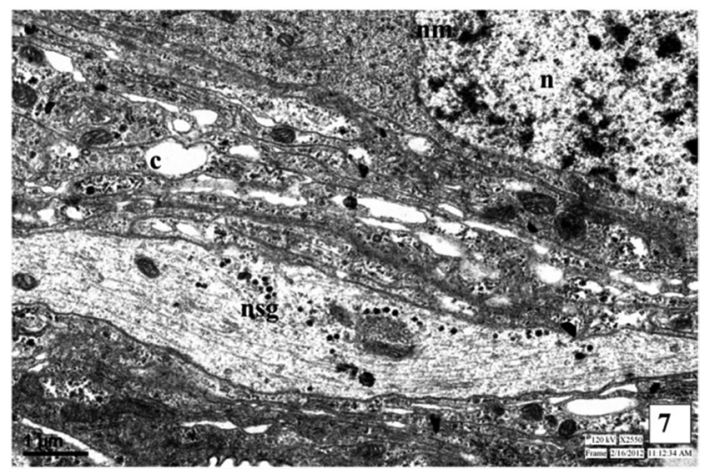

Fig. 7. Neurosecretory pathways in the pars intercerebralis of third instar larva showing nucleus $(\mathrm{N})$, nuclear membrane (NM), canaliculi (C) and transport of neurosecretory granules (NSG).

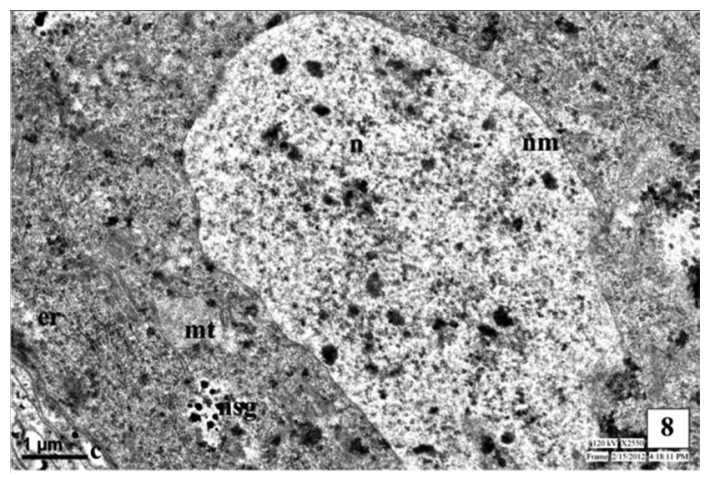

Fig. 8. Neurosecretory cell in the pars intercerebralis of fourth instar larva of $A$. mylitta showing nucleus (N), nuclear membrane (NM), endoplasmic reticulum (ER), mitochondria (MT), neurosecretory granules (NSG) and canaliculi (C).

$4.25 \mu \mathrm{m}$ to $8.75 \mu \mathrm{m}$. The nuclear membrane consists of two layers, inner $44.25 \mathrm{~nm}$ and outer $23 \mathrm{~nm}$ in thickness. The outer 


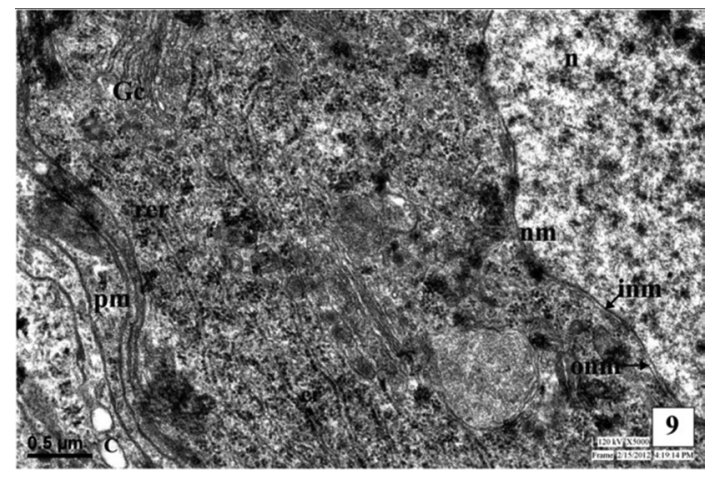

Fig. 9. Neurosecretory cell in the pars intercerebralis of fourth instar larva of $A$. mylitta showing nucleus $(\mathrm{N})$, outer nuclear membrane (ONM), inner nuclear membrane (INM), plasma membrane (PM), rough endoplasmic reticulum (RER), mitochondria (MT), Golgi complex (GC) and canaliculi (C).

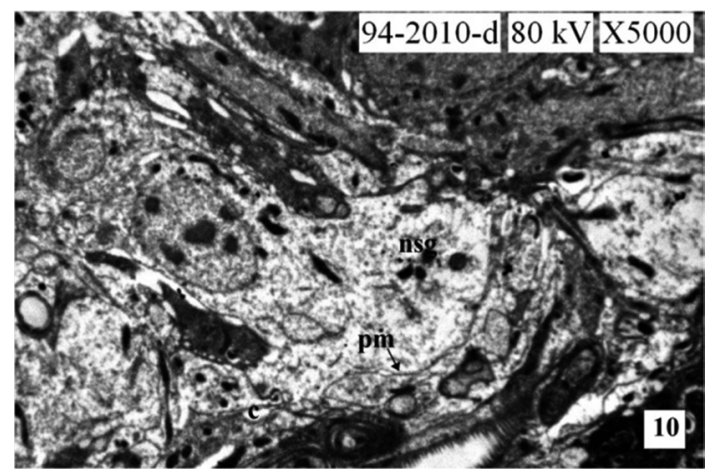

Fig. 10. Neurosecretory cell showing the release of neurosecretory granules of fifth instar larva of $A$. mylitta showing nucleus (N), neurosecretory granules (NSG), canaliculi (C).

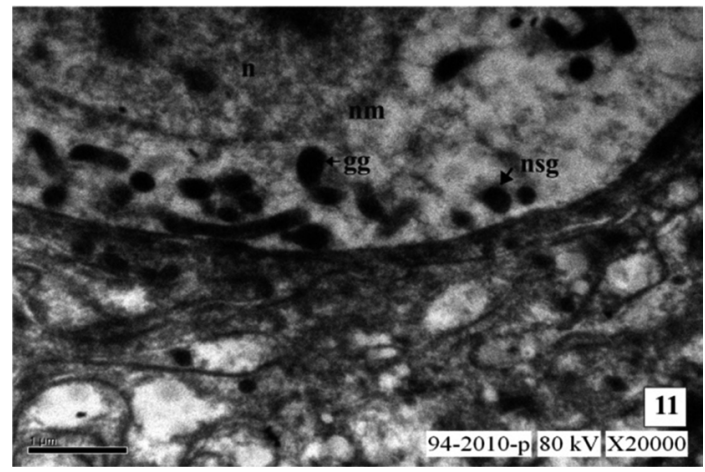

Fig. 11. Formation and release of neurosecretory granules (NSG) from the neurosecretory cell of fifth instar larva of A. mylitta. Nucleus (N), Golgi complex (GC), plasma membrane (PM) of neurosecretory cell, canaliculi $(\mathrm{C})$ between the neuroglial processes.

layer of nucleus is associated with the endoplasmic reticulum. The mitochondria are distributed throughout the perikarya of

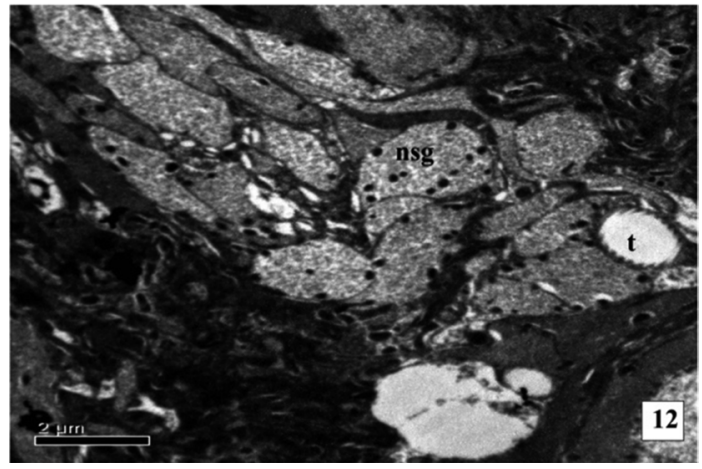

Fig. 12. Neurosecretory granules in the in the axonal endings of medial neurosecretory pathways inside the brain of fifth instar larva of $A$. mylitta. Neurosecretory granules (NSG), Trachiole (T).

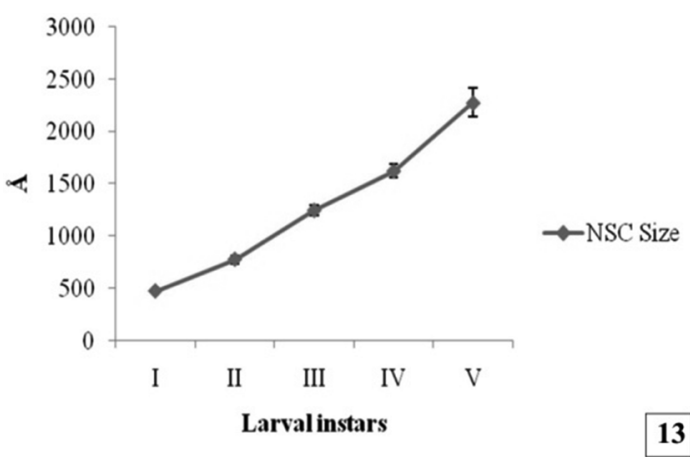

Fig. 13. Size of neurosecretory granules from first to fifth instar larva of $A$. mylitta.

Abbri: I-first instar larva, II-second instar larva, III-third instar larva, $I V$-fourth instar larva and $V$-fifth instar larva.

the neurosecretory cells. The mitochondria in number in the cell as compared to the first instar larva. Golgi complexes are also appeared in the cytoplasm. The canaliculi are associated with the plasma membrane of NSC for the direct release of NSM in to the blood sinus.

The NSG are closely associated with ER and MT. The size of NSG increases up to $776 \AA$. The amount of NSG increases in quantity in the cytoplasm of NSC, neurosecretory pathways and axonal endings (Fig. 4-5 and Fig. 13).

\section{Ultrastructure of NSC of III instar}

The ultrastructure of neurosecretory cells in the third instar larva is similar to the I and II instars. The spherical big sized nuclei with double layered nuclear membrane (NM) are observed at centre of the cell. The increased number of cell organelles like, mitochondria, Golgi bodies and endoplasmic reticulum is well evident in the perikarya. The organelles are observed in close vicinity with 
each other and are involved in the synthesis of NSG. The plasma membrane of NSC is attached with the canaliculi.

The NSG are well evident in the cytoplasm and the axonal endings and neurosecretory pathways of the NSC. The NSG measures about $1245 \AA$ in diameter (Fig. 6-7 and Fig. 13).

\section{Ultrastructure of NSC of IV instar}

The neurosecretory cells in the pars intercerebralis of fourth instar larva are similar to the cells of III instar larva. The mitochondria (MT) are distributed in the cytoplasm of the cells. The Golgi bodies and the channels of rough endoplasmic reticulum (RER) are well evident. They are closely associated with each other. The interrelationship between the organelles viz., MT, ER and Golgi bodies for the synthesis of NSM is well evident. The cell organelles increase in number indicated the excess secretion of NSM than in the third instar. The size of NSG increases than that in the third instar and measure about $1622 \AA$ in diameter. The NSG are observed in the perikarya, axonal endings of NSC and neurosecretory pathways of NSC (Fig. 8-9 and Fig. 13).

\section{Ultrastructure of NSC of $\mathrm{V}$ instar}

The NSC contains well developed nuclei enveloped by double layer nuclear membrane. Cell organelles are well developed and abundant in number. The endoplasmic reticulum (ER), Golgi complex (GC) and mitochondria (MT) are well distinguished and are closely associated with the synthesis of NSM. The NSG are observed in the Golgi zone. The NSG are transported by the axons as well as the canaliculi to the corpora cardiaca (CC) and blood sinus. The neurosecretory pathways are distinctly observed. The synthesis of NSM is increased and the NSG are distributed in the perikarya and transported through axons. The NSG appeared spherical and dark black in colour. The NSG are increase in size and large sized granules are found in cytoplasm. The synthesis of NSM increases and the cells are full of NSG. The NSG are of two types, giant granules (GG) measuring about $7025 \AA$ and smaller elementary granules (EG) measuring about $2275 \AA$ in diameter.

During larval development the secretory activity by the NSC are observed predominantly. The NSG are observed frequently in the Golgi zone, cytoplasm, neurosecretory pathways and axonal endings of cells. The size of NSG increases gradually from the first to the fifth instars larva (Fig. 10-12 and Fig. 13).

\section{Discussion}

The electron microscopic study of the neurosecretory cells of tasar silkworm A. mylitta reveals the presence of neurosecretory granules (NSG). The NSG are scanty and occur in well defined membranous endoplasmic reticulum with Palade granules, the latter granules occur in the cytoplasm. By contrast, when the elementary granules are numerous, the rough endoplasmic reticulum becomes scanty. The elementary granules with membranous covering are frequently encountered in the Golgi zone. In the Golgi zone, some of the mitochondria are divided into small fragments and loose gradually their crestae.

The MNC in the pars intercerebralis of the larvae of $A$. mylitta exhibit the presence of rough endoplasmic reticulum and Golgi bodies and release of EG in MNC of tasar silkworm larvae (Fujita's, 1957) similar to those detected in the neurohypophysis nerve fibers of many vertebrates (Bargmann, 1958; Duncan, 1956; Enami and Imai, 1958; Green and Van Breemen, 1955; Heartmann, 1958; Palay, 1957; Sano and Knoop, 1959), as well as in the corpus allatum of Pimpla turionllae (Aydin Özlük et al., 2011) and in the neurosecretory cells of Philosamia (Nishiitsutsuji-Uwo, 1960, 1961; Tembhare, 1980). Similar electron dense granules were also observed in the cephalic neurosecretory cells in larva of Hyphantria cunea drury (Panov and Melnikova, 1974) and Bombyx mori MNC (Bassurmanova and Panov, 1967).

On the basis of the dimension, A. mylitta NSG can be considered equivalent to neurosecretory granules detected earlier in the neurohypophysis (Bargmann, 1958, Duncan, 1956; Fujita, 1957; Green and Van Breemen, 1955; Hartmann, 1958; Palay, 1957), in the caudal neurosecretory system of vertebrates (Enami and Imai, 1958; Sano and Knoop, 1959) and in the neurosecretory terminal organ in the invertebrates (Knowles, 1958; Meyer and Pfugfelder, 1958; Hodge and Chapman, 1958). In Philosamia a particular feature of mitochondria forming a rosary of ellipsoidal bodies occur near the Golgi membranes and indicating their involvement in the synthesis of NSG (Nishiitsutsuji-Uwo, 1960, 1961; Beams and Kessel, 1968). In A. mylitta Golgi apparatus is related to formation of secretory granules since they frequently encountered within the Golgi zone. The association of mitochondria, Golgi complexes and endoplasmic reticulum confirms their role in the synthesis of NSM and supports the observation of earlier workers. 
Scharrer and Scharrer (1944) noticed the neurosecretory granules in the neurosecretory cells of Leucophaea and their migration along the axons to corpora cardiaca. In Lepidoptera, the neurosecretory granules in the pars intercerebralis are transported along axons to reach the corpora cardiaca and corpora allata (Arvy et al., 1953; Kobayashi, 1957; Ichikawa and Nishiitsutsuji-Uwo, 1960, 1961; Ichikawa and Tekahashi, 1959; Nishiitsutsuji-Uwo, 1960, 1961; Ozluk et al., 2011). Some workers also reported the direct release of neurosecretory material from the cell perikaryon to the blood sinus (Rehm, 1950; Williams, 1952; Nishiitsutsuji-Uwo, 1960, 1961).

The electron micrographs indicate that the neurosecretory cells in the pars intercerebralis are enmeshed by the neuroglial cell processes, among which there exist canaliculi communicating with a blood sinus. The canaliculi are in contact with plasma membrane of the neurosecretory cells. Although elementary granules cannot be seen within the canaliculi, these structures are apparently convenient for direct secretion of the secretory material from cells into blood system of $A$. mylitta.

From the above observations, it may be summarized that the formation of the elementary granules occurres in the close association within the Golgi zone and it is a continuous process from the I to $\mathrm{V}$ instar larvae.

\section{Acknowledgement:}

We thank Dr. D. B. Tembhare, Ex-professor and Head, Dept. of Zoology RTM Nagpur University Nagpur for valuable comments and discussion on our research. This study was supported by University Grants Commission for providing financial support for major research project $\{F$. No. 36202/2008(SR)\} and for Rajiv Gandhi National Fellowship.

\section{References}

Arvy L, Bounhiol JJ, Gabe M (1953) Deroulement de la neurosecretion protocerebralechez Bombyx mori L. au cours du developpement post-embryonnaire. C R Acad Sci (Paris) 236, 627629.

Aydin Ö, Nursel G, Ahmed M (2011) Ultrastructural description of the corpora allata of Pimpla turionellae L. (Hymenoptera: Ichneumonidae). African Journal of Biotechnology Vol 10(19),
3784-3789.

Bargmann W (1958) Elektornemikroskopische Untersuchungen an der Neurohypophyse, S., 4-12. Zweites Internat. Symposium uber Neurosekretion, Lund, Berlin - Gottingen -heiddelberg: Springer, pp. 1-6

Bassurmanova OK, Panov AA (1967) Structure of the neurosecretory system in Lepidoptera. Light and electron microscopy of type $\mathrm{A}^{\prime}$-neurosecretory cells in the brain of normal and starved larvae of the silkworm Bombyx mori. General and Comparative Endocrinology. 9, 245-262.

Beams HW, Kessel RG (1968) The Golgi apparatus: structure and function. Int. Rev. Cytol. 23, 209-276.

Duncan D (1956) An electron microscope study of the neurohypophysis of a bird, Gallus domesticus. Anat. Rec. 125, 457-473.

Enami M, Imai K (1958) Studies on neurosecretion XII. Electron microscopy of the secret granules in the caudal neurosecretory system of the eel. Proc. Jap. Acad. 34 (13), 164-168.

Fujita H (1957) Electron microscopic observations on the neurosecretory granules in the pituitary posterior lobe of dog. Arch Hist jap 12, 165-172.

Green JD Van Breemen VL (1955) Electron microscopy of the pituitary and observations on neurosecretion. Amer J Anat 97, 177-227.

Heartmann JF (1958) Electron microscopy of the neurohypophysis in normal and histamine treated rats. Z Zellforsch 48, 291-308.

Hodge MH Chapman GB (1958) Some observations on the fine structure of the sinus gland of a land crab, Gecarcinus lateralis. J Biophys Biochem Cytol. 4, 731-742.

Ichikawa M Nishiitsutsuji-Uwo J (1959) Studies on the role of the corpus allatum in the Eri-silkworm, Philosamia cynthia ricini. Biol Bull 116, 88-94.

Ichikawa M Nishiitsutsuji-Uwo J (1960) Studies on the insect metamorphosis. VII. Effect of the brain hormone to the isolated abdomen of the Eri-silkworm, Philosamia cynthia ricini. Mem Coll Sci Univ Kyoto Ser 27(B), 9-15.

Ichikawa M Takahashi S (1959) Study on the endocrine activity of Bombyx-allatum in the diapausing Philosamia-pupa. Mere Coll Sci Univ Kyoto Ser 26(B), 249-252.

Nishiitsutsuji-Uwo J (1960) Fine structure of neurosecretory system in Lepidoptera. Nature (Lond.) 188, 953-954.

Nishiitsutsuji-Uwo J (1961) Electron microscopic studies on the neurosecretory system in Lepidoptera. J Zeitschrift fur Zellforschung, 54, 613-630. 
Knowles FGW (1958) Electron microscopy of crustacean neurosecretory organ. Zweites Internat. Symposium uber neurosecretion, Lund, Berlin-Gottingen-Hidelberg: Springer 1-6 (S), 105109.

Kobayashi M (1957) Bull Seric exp Stat Tokyo. 15, 181 (in Japanese with English summary).

Meyer GF Pflugfelder UO (1958). Elektronenmikroskopische Untcrsuchungen an den Corpora cardiaca yon Carausius morosus BR Z Zellforsch. 48, 556--564.

Özlük A Gül N Muhammed A (2011) Ultrastructural description of the corpora allata of Pimpla turionellae L. (Hymenoptera: Ichneumonidae). African Journal of Biotechnology. Vol. 10(19), 3784-3789.

Palay SL (1957) The fine structure of the neurohypophysis. In: Progress in Neurobiology. Vol II edit by H. WAELSCH. New York: P. B. Hoeber

Panov AA Melnikova EJ (1974) Structure of the neurosecretory system in Lepidoptera : II. Light and electron microscopy of the medial neurosecretory cells in larval brain of Hyphantria cunea drury (Lepidoptera). J General and Comparative Endocrinology. Vol 23 (4), 361-375

Rehm M (1950) Sekretionsperioden neurosekretorischer Zellen im Gehirn von Ephestia kiihniella Z Naturforsch. 5, 167-169.

Sano Y Knoop A (1959) Elektronenmikroskopische Untersuchungen am kaudalen neurosekretorischen System yon Tinca vulgaris. Z Zellforsch 49, 464-492.

Scharrer E Scharrer S (1944) Neurosecretion VI. A comparison between the intercerebralis-cardiacum-allatum system of the insects and the hypothalamo-hypophyseal system of vertebrates. Biol Bull 87, 242-251.

Tembhare DB (1980) An electron microscopic study of the neurosecretory pars intercerebralis- Corpus cardiacum system in larvae of the Dragonfly, Aeschna cyanea (Muller) (Odonata: Aeschniidae). J Z mikrosk.-anat Forsch Leipzing. 94, 60-72.

Williams CM (1952) Morphogenesis and the metamorphosis of insects. Harvey Lect 47, 126-155. 